\title{
MANGNGADE: CIRI TRADISI MEGALITIK DI DESA WANUWARU, MALLAWA, MAROS
}

\author{
Mangngade: The Characteristic of Megalithic Tradition \\ in Wanuawaru Village, Mallawa, Maros
}

\author{
Andi Muh. Saiful \\ Balai Arkeologi Sulawesi Selatan \\ Jl. Pajjaiyang No. 13 Sudiang Raya Makassar, Indonesia \\ ifulk_fullah@yahoo.co.id
}

Naskah diterima: 15/08/2018; direvisi: 19/09-28/11/2018; disetujui: 30/11/2018

Publikasi ejurnal: 21/12/2018

\begin{abstract}
Mangngade or 'performing custom' is a common activity in Wanuawaru Village, Mallawa District, Maros Regency, which is conducted in December and January. The problem in this research is how Wanuawaru villagers doing it and how position Manggade to Wanuawaru Villagers. There are three stages during the Mangngade procession namely visiting salo, gathering in Saoraja, and gathering in Bulu Posso. In Mangngade, the community performs prayers related to agriculture to avoid natural disasters, to beg for peace, safety, and success of personal life. The methods of data collection are ethnographic method and archaeological data recording. The results of data recording are then analyzed using concept in megalithic culture. Based on those data, it is finally concluded that Mangngade is the character of a megalithic tradition that is still carried out by the Wanuawaru villagers from generation to generation for confession about their community.
\end{abstract}

Keyword: Manggade, Megalithic, Ritual.

\begin{abstract}
Abstrak
Mangngade atau 'menjalankan adat' merupakan kegiatan masyarakat di Desa Wanuawaru, Kecamatan Mallawa, Kabupaten Maros, yang dilakukan pada bulan Desember dan Januari. Masalah yang diangkat dalam penelitian ini, yaitu bagaimana proses acara Mangngade dan kedudukannya dalam masyarakat Desa Wanuawaru. Terdapat tiga tahap saat prosesi Mangngade, yaitu mengunjungi salo, berkumpul di Saoraja, dan berkumpul di Bulu Posso. Dalam Mangngade, masyarakat melakukan doa-doa yang berkaitan dengan pertanian, terhindar dari bencana alam, kedamaian, keselamatan dan kesuksesan kehidupan pribadi. Adapun metode pengumpulan data yang digunakan yaitu, metode etnografi dan perekaman data arkeologi. Hasil perekaman data kemudian dianalisis dengan menggunakan konsep dalam kebudayaan megalitik. Berdasarkan data tersebut akhirnya disimpulkan bahwa Mangngade merupakan ciri tradisi megalitik yang masih dijalankan masyarakat Desa Wanuawaru secara turun temurun dari leluhurnya dalam membangun pengakuan keberadaan kelompoknya.
\end{abstract}

Kata Kunci: Mangngade, Megalitik, Ritual.

\section{PENDAHULUAN}

Mangngade merupakan Bahasa Bugis yang diartikan "menjalankan adat". Adat dalam hal ini adalah acara tahunan yang digelar pada tiap bulan Desember dan Januari pada beberapa tempat di Kecamatan Mallawa ${ }^{1}$. Keberlangsungan Mangngade menunjukkan prosesi budaya masyarakat

\footnotetext{
${ }^{1}$ Tempat tersebut, yaitu Desa Wanuawaru, Desa Batu Putih, dan Desa Gattareng Matinggi
}

yang secara turun temurun terus dijalankan dengan menggunakan alam sebagai media simbolik.

Unsur-unsur yang teramati sehingga Mangngade merupakan rangkaian dari budaya yang berlangsung secara turun temurun, yaitu dalam pelaksanaannya menggunakan alam ${ }^{2}$, benda alam ${ }^{3}$, hewan,

\footnotetext{
${ }^{2}$ Gunung, bukit, sungai, hutan.

${ }^{3}$ Batu, pohon, kayu, daun
} 
adanya penyerahan sesajian, dan keterlibatan sandro ade' (dukun). Tingkah laku tersebut mirip dengan tingkah laku sebagian masyarakat pada tempat lain di wilayah Sulawesi Selatan yang pernah ditemukan.

Prosesi serupa yang ditemui di wilayah Sulawesi Selatan, yaitu di Situs Sewo, Soppeng. Pada situs ini orang-orang melakukan pemujaan yang berkaitan dengan pertanian dengan menggunakan media batu (Andari, 2001, 2006). Demikian pula di Situs Bulu Bongki, Kajang, Bulukumba, masyarakat melakukan permintaan kesuksesan, keselamatan, keberhasilan panen, kesembuhan dari penyakit yang mendera dengan persembahan hewan tertentu (Umar, 2002). Lalu di Situs Gantarang Keke, Bantaeng, masyarakat melakukan acara Pakjukukang sebagai ungkapan rasa syukur berkaitan dengan keberhasilan panen yang ditujukan kepada Karaeng Loe yang dianggap sebagai Tomanurung (Duli, 2008; Suryatman, 2011). Kemudian di Situs Bulo-Bulo, Sinjai, masyarakat melakukan pemujaan dengan menaruh daun pandan di atas batu (Hasanuddin, 2011b), dan di Situs Buntu Marari, Enrekang, masyarakat melakukan penyembelihan hewan pada batu temu gelang setelah berlangsungnya panen hasil pertanian (Hasanuddin, 2011b).

Perilaku masyarakat pada situs yang disebutkan di atas merupakan Tradisi Megalitik (Andari, 2001, 2006; Duli, 2008; Hasanuddin, 2011a; Suryatman, 2011; Umar, 2002). Megalitik adalah upacara pemujaan terhadap nenek moyang yang dilakukan masyarakat secara turun temurun dengan menggunakan media batu, baik itu batu yang berukuran besar ataupun yang kecil,bahkan tanpa media tersebut (Duli, 2008). Oleh karena itu, tradisi tersebut merupakan budaya masyarakat yang memperlihatkan relasinya dengan artefak (Harris, 2006). Dengan demikian, berdasarkan fenomena yang ditemukan dalam pelaksanaan Mangngade di Desa
Wanuawaru yang menggunakan media alam dan hewan tampaknya memiliki kesamaan dengan aktivitas masyarakat pada situs megalitik di Sulawesi Selatan yang telah diteliti. Oleh karena itu, dalam penelitian ini penulis membangun asumsi bahwa Manggade dapat dipersepsikan sebagai aktivitas bercirikan tradisi megalitik yang masih berlangsung hingga saat ini di Desa Wanuawaru, Kecamatan Mallawa, Kabupaten Maros, Sulawesi Selatan. Beranjak dari uraian dan asumsi yang telah dibangun, maka pertanyaan dalam tulisan ini adalah: Bagaimana proses Mangngade yang berlangsung di Desa Wanuawaru? dan bagaimana kedudukan Mangngade dalam masyarakat Desa Wanuawaru?

\section{METODE PENELITIAN}

Penelitian ini dilakukan pada tanggal 26 Desember 2017. Metode pengumpulan data yang diterapkan, yaitu etnografi dan survey. Etnografi adalah deskripsi dan analisa suatu masyarakat yang didasarkan pada penelitan lapangan (Pinasti, 2007). Dalam penelitian ini, penulis mengikuti rangkaian acara Manggade dan melakukan wawancara terhadap tokoh masyarakat, masyarakat awam dan pemuda yang ikut dalam kegiatan tersebut. Ada tiga resonden yang terpilih yaitu, Rudi (35), Amir (40) dan Monro (68). Adapun informasi yang akan didapatkan dalam wawancara tersebut, yaitu tahapan acara Mangngade, tujuan dilakukannya Mangngade, aturan-aturan dalam Mangngade, makna yang dipahami masyarakat dalam kegiatan Mangngade, dan orang-orang yang terlibat dalam acara Mangngade. Selain menggunakan metode di atas, penelitian ini juga menggunakan metode survey, yaitu mengamati sebaran artefak yang digunakan dalam acara Mangngade.

Pertimbangan pentingnya mendapatkan informasi di atas untuk melihat gejala-gejala acara dalam Manggade yang berkaitan dengan masa lalu baik itu dalam konteks arkeologi, konteks sejarah, atupun 
konteks masa kini. Oleh karena itu, dengan mendapatkan informasi tersebut diharapkan dapat diketahui makna dan kedudukan Manggade yang sesungguhnya dalam masyarakat Desa Wanuawaru.

Selanjutnya, survey dilakukan dengan mengunjungi objek-objek yang digunakan dalam acara Mangngade dan pengambilan titik kordinat lokasi. Objek yang digunakan tersebut kemudian direkam dengan melakukan pendeskripsian dan melakukan pemotretan terhadap media yang digunakan ataupun ketika aktivitas Mangngade sedang berlangsung. Hasil perekaman data, baik wawancara ataupun pendeskripsian kemudian dianalisis dengan menggunakan konsep kehidupan dalam kebudayaan megalitik.

\section{HASIL DAN PEMBAHASAN}

\section{Lokasi Penelitian}

Lokasi penelitian terletak di Dusun Wanuawaru, Desa Wanuawaru, Kecamatan
Mallawa, Kabupaten Maros. Secara geografis terletak pada $4^{\circ} 44^{\prime} 59.5^{\prime \prime}$ LS dan $119^{\circ} 54^{\prime} 47.8^{\prime \prime}$ BT. Situs ini dapat dicapai dengan menggunakan kendaaraan roda dua dan roda empat dengan waktu tempuh 30 menit dari jalan poros Maros-Bone yang melintasi Desa Batu Putih. Adapun media yang dijadikan sarana dalam Manggade, yaitu:

\section{a. Batu Melingkar}

Batu melingkar adalah susunan batu yang diletakkan di atas tanah membentuk lingkaran. Batu-batu tersebut saling berhimpitan tanpa ada celah dan saling menumpuk hingga menjadi dua tingkat dalam susunanannya. Tinggi susunan batu tersebut $10 \mathrm{~cm}$ sampai $20 \mathrm{~cm}$. Batu tersebut merupakan batu kerakal dan batu brangkal vulkanik yang kondisinya berlumut. Diameter batu melingkar, yaitu 10 meter. Batu melingkar terletak pada lereng yang landai di Bulu Posso. Letaknya di batasi

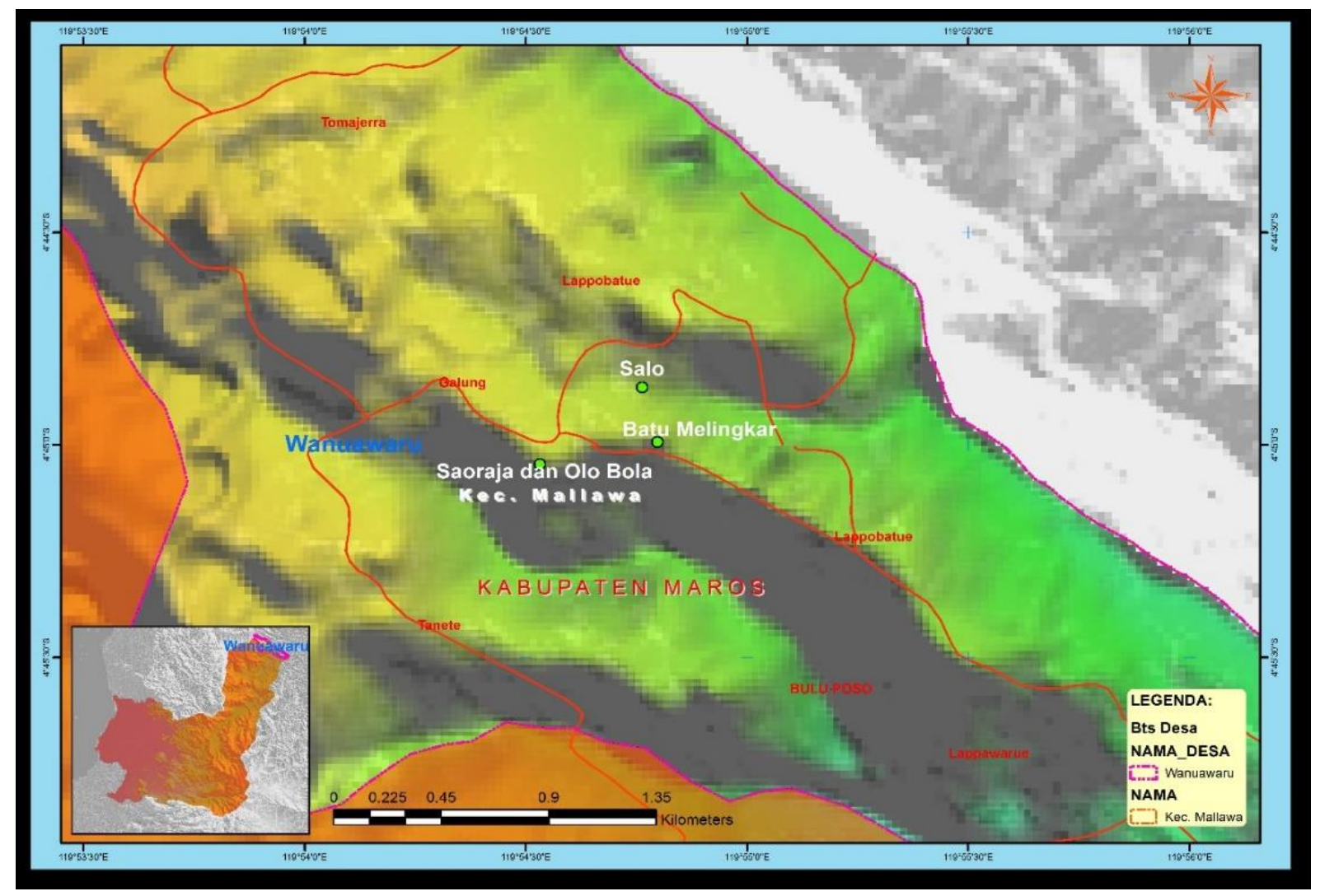

Gambar 1. Peta Desa Wanuawaru dan letak prosesi Mangngade

(Sumber: Dokumentasi Fardi Alisyahdar, tahun 2018) 


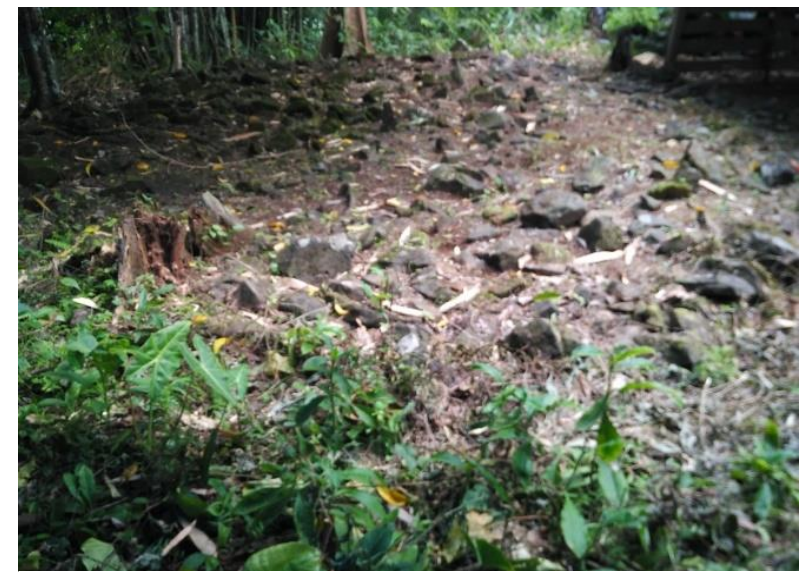

Gambar 2. Foto Batu Melingkar (Sumber: Dokumentasi Andi Muh. Saiful, Tahun 2017)

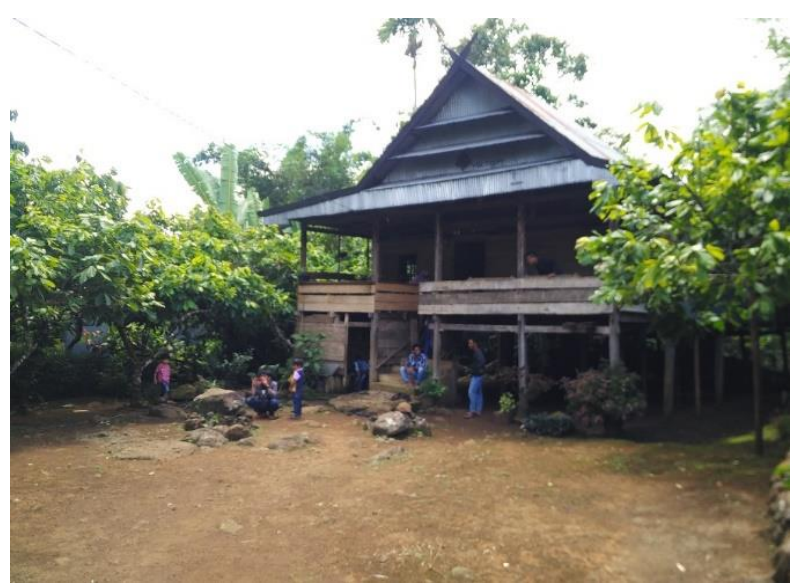

Gambar 3. Foto rumah Sauraja

(Sumber: Dokumentasi Andi Muh. Saiful, Tahun

2017)

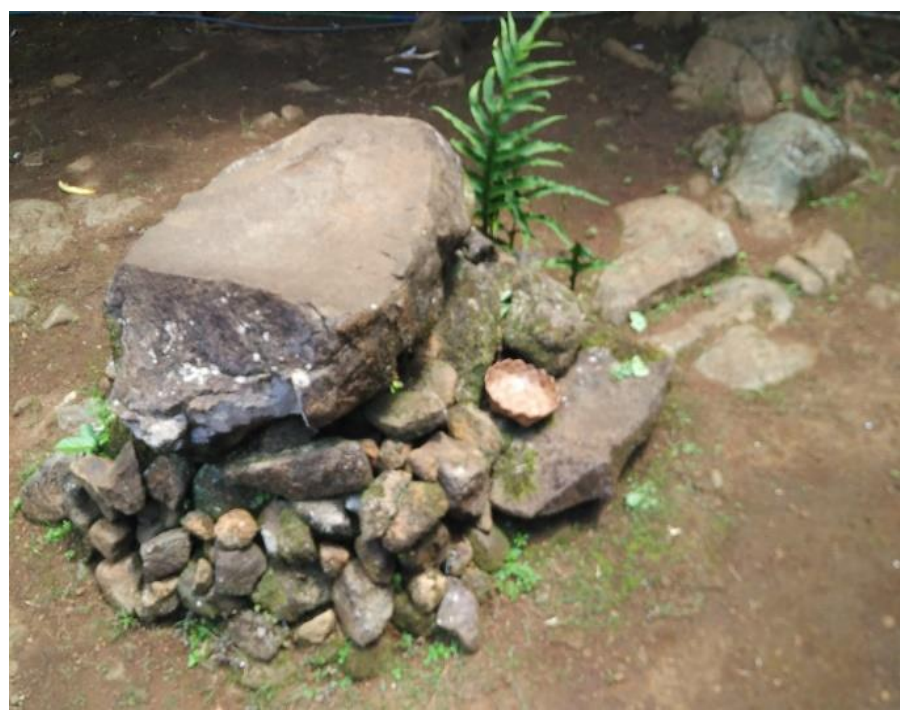

Gambar 4. Foto Batu Olo Bola

(Sumber: Dokumentasi Andi Muh. Saiful, Tahun 2017)

kebun coklat dan lereng terjal di sebelah utara, di sebelah selatan dibatasi dengan jalan desa dan rumah penduduk, di sebelah barat dibatasi kebun kemiri dan coklat, lalu di sebelah timur dibatasi dengan lereng terjal.

\section{b. Saoraja}

Saoraja merupakan rumah adat penduduk Wanuawaru dengan arsitektur rumah panggung yang memiliki tiang sebanyak 30. Rumah ini terlihat sama dengan rumah penduduk pada umumnya. Unsur ketuaannya dan ciri arsitektur rumah adat Bugis pada umumnya tidak menonjol. Atap bagian depan rumah (timpalaja) memiliki tiga susunan. Bagian depan terdapat teras dan di tengah-tengahnya terdapat tangga naik ke rumah. Dinding rumah bagian depan terbuat dari susunan papan tanpa memiliki motif hias. Pada dinding ini hanya terdapat satu ventilasi. Saoraja ini menghadap ke utara.

\section{c. Olo Bola}

Olo Bola merupakan bongkah batu vulkanik yang berukuran panjang $100 \mathrm{~cm}$, lebar $50 \mathrm{~cm}$, dan tinggi $50 \mathrm{~cm}$ yang 
diletakkan di depan Saoraja. Batu ini berada di atas susunan batu kerakal dan batu brangkal vulkanik. Batu ini memanjang dari timur ke barat. Di sebelah selatannya atau pada konsentrasi tumpukan batu kerakal terdapat batu datar yang di atasnya ditaruh wadah berukuran kecil terbuat dari daun kelapa dan terdapat pula lipatan daun yang tampak masih segar.

\section{d. Salo}

Salo atau sungai terletak di sebelah utara Saoraja, oleh masyarakat setempat menyebutnya sungai Lappo Batu. Waktu tempuh yang digunakan untuk mencapai salo sekitar 45 menit dengan berjalan kaki melewati sawah dan perkebunan penduduk. Salo ini setiap waktu terus mengalirkan air ke persawahan penduduk.

\section{Proses Mangngade}

Mangngade merupakan prosesi upacara adat yang dilakukan oleh masyarakat Desa Wanuawaru setiap tahun di bulan Desember dan Januari. Dalam proses Manggade ada tiga tahapan yang dilakukan, yaitu tahap mengunjungi Salo, Saoraja, dan Bulu Posso.

Mengunjungi Salo merupakan proses awal. Kunjungan ke Salo melakukan pappasoro (menangkal banjir dan angin) dengan harapan agar hasil pertanian menjadi baik. Di tempat ini dilakukan pula acara maccera yaitu pemotongan hewan berupa ayam dan kambing. Maccera (persembahan) dilakukan agar padi tidak merah, terhindar dari bencana alam yaitu banjir dan angin kencang.

Saoraja berkaitan dengan pakkatuo (masalah kehidupan), di saoraja warga datang membawa sokko (makanan yang terbuat dari beras ketan) dan ayam yang masih hidup. Mereka yang membawa ayam harus sesuai dengan jenis kelamin, pria membawa ayam jantan dan wanita membawa ayam betina. Ketika acara telah berlangsung di tempat ini maka gendang akan ditabuh. Ada tiga tahap yang dilakukan di Saoraja, yaitu maggenrang (memainkan gendang), ma'baca (membaca doa), dan manre (makan).

Tahap terakhir diadakannya acara Mangngade adalah mengunjungi Bulu Posso. Bulu Posso merupakan tempat teramai karena seluruh warga akan berkumpul menyaksikan upacara. Acara ini mengandung pesan passappo (pertahanan diri). Acara akan dimulai di tempat ini ketika sanro ade' (dukun) serta masyarakat datang dengan berjalan beriringan disertai bunyi

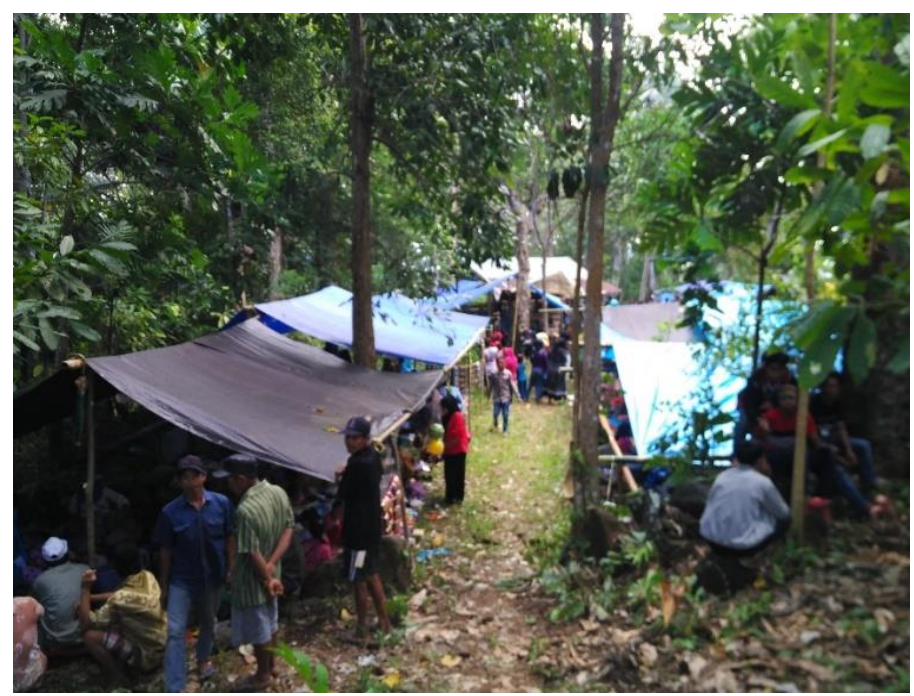

Gambar 5. Suasana di lokasi acara Mangngede di Bulu Posso (Sumber: Dokumentasi Andi Muh. Saiful, Tahun 2017) 


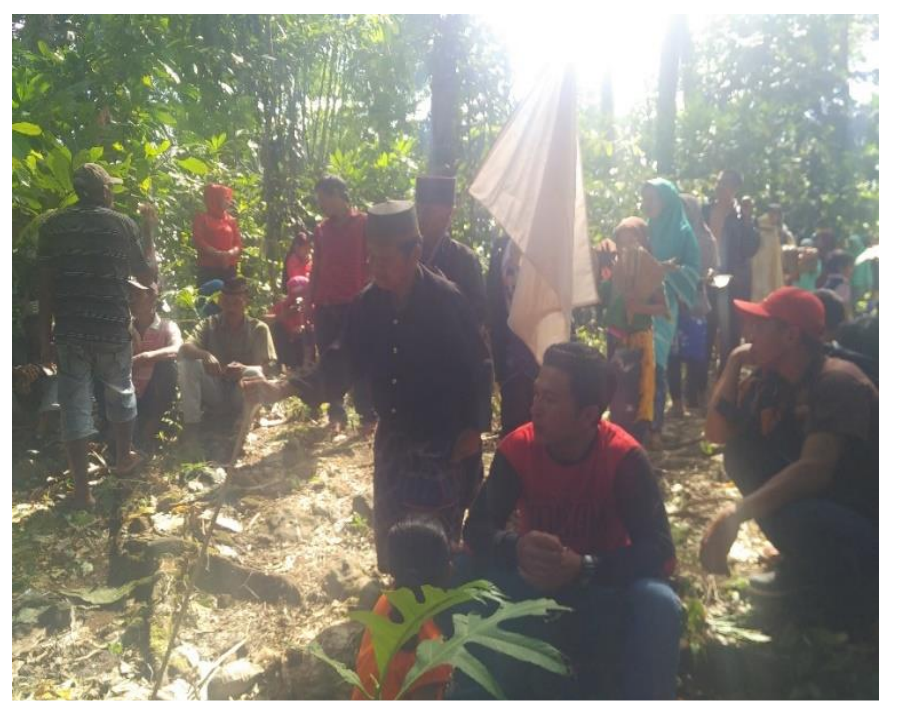

Gambar 6. Kedatangan ketua adat di Bulu Posso

(Sumber: Dokumentasi Andi Muh. Saiful, Tahun 2017)

gendang. Sanro ade' berjalan paling depan, dibelakangnya diikuti oleh perempuan dewasa dengan membawa dupa yang terbuat dari kemiri, lalu disusul pembawa bendera dan pembawa walasuji. Setelahnya, ada penabuh gendang dan kembali perempuan dewasa yang membawa keranjang berisi sokko (makanan yang terbuat dari beras ketan) dan masakan ayam, serta ayam yang masih hidup.

Di depan batu melingkar tepatnya di bawah bangunan yang terbuat dari kayu dan beratap seng, orang-orang berkumpul yang dominan perempuan, penabuh gendang, dan sanro ade' (dukun adat). Sandro ade'duduk di bagian tengah paling belakang, penabuh genderang paling depan dekat dengan batu melingkar sebelah kiri, dan seorang lelaki tua di sebelah kanan batu melingkar. Ruang yang kosong ditempati perempuan, sebagian di antaranya ada yang memegang dupa. Bagian tengah diletakkan kain putih sehingga menutupi rangka kecil berbentuk persegi yang berukuran lebar $50 \mathrm{~cm}$ dan tinggi $50 \mathrm{~cm}$. Di tempat ini pula makanan berupa sokko diletakkan mengisi ruang kosong, sehingga tampak sokko dikelilingi oleh orang dalam bangunan tersebut.

Upacara di batu melingkar diawali dengan bunyi gendang, lalu sanro ade' membacakan sesuatu sambil memegang sabuk kelapa yang sedang terbakar. Sanro ade' sesekali menabur biji-bijian dan meniupnya. Sabuk kelapa kemudian dibawa bergerak mengelilingi batu melingkar dengan cara memindahkan ke tiap orang yang berada di tepi batu melingkar tersebut. Sabuk itu diarak mengelilingi batu melingkar sebanyak 3x dari arah barat ke timur dan sekali dari timur ke barat. Saat prosesi ini berlangsung, setiap orang tidak dibolehkan masuk ke dalam batu melingkar. Setelah sabuk kelapa mengelilingi batu melingkar, sanro ade' kembali membaca sesuatu sambil meletakkan tangan kanan ke tanah dengan posisi jari kelingking berada di bawah dan ibu jari berada pada posisi atas. Setelah itu, sandro ade' mengambil ayam dan mengucapkan doa-doanya, lalu ayam tersebut di masukkan sejenak pada rangka persegi yang ditupi kain putih di tepi batu melingkar. Lalu ayam putih kemudian di lepas atau diberikan pada orang-orang yang menginginkannya.

Prosesi selanjutnya adalah tiap warga akan datang membawa ayam masuk dalam bangunan, dan duduk di sebelah kiri sanro ade' kemudian memberikan ayam tersebut kepada sanro ade'. Selanjutnya, sanro ade' akan membacakan sesuatu kemudian si pembawa ayam akan menggerakkan kedua tangannya ke arah 


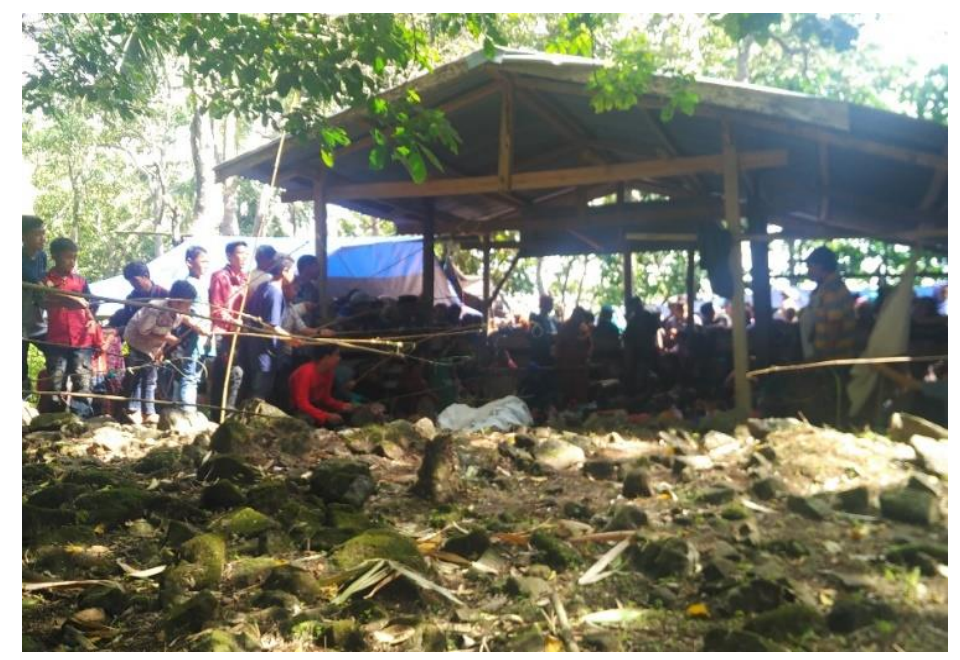

Gambar 7. Acara puncak Mangngade di Batu Melingkar

(Sumber: Dokumentasi Andi Muh. Saiful, Tahun 2017)

ayam tersebut. Setelah itu, ayam akan di masukkan ke kain putih lalu dikeluarkan dan dilepas. Proses ini terus berjalan sampai tidak ada lagi warga yang membawa ayam kepada sanro ade'.

Proses upacara di batu melingkar merupakan proses passappo (melindungi diri dari bahaya). Sembari proses melepas ayam berjalan, proses maccera juga dilakukan ditempat ini yang ditandai dengan acara sabung ayam. Sabung ayam hanya dilakukan sekali. Proses maccera ini dimaknai agar tidak terjadi pertumpahan darah sesama manusia. Mereka yang hadir di tempat ini melakukan niat dan ketika niat itu terwujud maka mereka akan kembali datang melepas ayam sebagai bentuk penepatan janji karena niatnya tersebut. Mereka yang datang adalah mereka yang niatnya telah terkabul.

\section{Mangngade Sebagai Aktivitas Bercirikan Tradisi Megalitik.}

Tradisi Megalitik adalah budaya yang umumnya diwujudkan dalam bentuk batu-batu besar yang pendiriannya dimaksudkan sebagai lambang atau sarana pemujaan terhadap arwah nenek moyang (Simanjuntak \& Widianto, 2012). Dalam perkembangannya megalitik tidak selalu berkaitan dengan batu besar atau monumen besar, tetapi hal yang berkaitan dengan pemujaan nenek moyang dengan menggunakan batu kecil ataupun kayu dapat dikategorikan sebagai budaya megalitik (Duli, 2008). Tradisi megalitik yang berkembang di Sulawesi Selatan dibangun oleh aspek religi dan aspek sosial. Aspek religi berkaitan dengan persembahanpersembahan dan aspek sosial budaya megalitik menggambarkan kehidupan yang terorganisir yang didalamnya terdapat pemimpin dan masyarakat yang dipimpin (Hasanuddin, 2016).

Berdasarkan hasil survey dan wawancara pada kegiatan Manggade di Desa Wanuawaru, unsur dalam pelaksanaannya diisi oleh adanya aktivitas persembahan-persembahan. Persembahan tersebut dilakukan di Salo (sungai). Salo merupakan tempat pertama yang harus dikunjungi oleh masyarakat. Pada tempat ini, masyarakat melakukan persembahan yang diwujudkan dengan penyembelihan hewan berupa ayam dan kambing. Maksud diadakannya penyembilahan itu adalah agar terhindar dari bencana alam yang dapat memberikan hasil panen yang melimpah.

Persembahan berikutnya ditemui di Batu Melingkar yang terletak di Bulu Posso. Pada tempat ini, masyarakat datang dengan membawa hewan berupa ayam. Tujuan masyarakat datang ke Batu Melingkar adalah mengharapkan adanya Passappo 
(pertahanan diri). Passappo yang diharapkan adalah agar terhindar dari hal-hal yang kelak dapat merugikan mereka. Sifat passappo tampaknya lebih pada keinginan perseorangan. Passappo tidak hanya dimaknai sebagai pengharapan tetapi juga mewujudkan pula melalui ungkapan kesyukuran. Pada acara ini, beberapa orang datang melepas ayam karena pengharapanpengharapan yang telah dibuat di tempat ini pada acara-acara Manggade sebelumnya telah terkabul.

Kegiatan Manggade di Desa Wanuawaru dilakukan secara komunal oleh masyarakat yang masih memegang budaya ini. Mangngade merupakan ajang berkumpul sanak keluarga atau pengingat akan kampung halaman mereka. Pada saat pelaksanaan Mangngade akan berlangsung tak jarang para penduduk desa Wanuawaru yang merantau datang mengikuti acara ini. Tujuannya adalah bentuk mewujudkan kesyukuran atas kehidupan yang telah dijalani di tanah rantau dan wujud penghormatan terhadap tanah leluhur mereka.

Pelaksanaan dilakukan dengan cara yang terorganisasi dan terstruktur. Dalam acara Mangngade terdapat sanro ade' (dukun adat) yang memimpin pelaksanaan acara di Batu Melingkar. Sanro ade' dalam posisinya adalah yang membacakan doa-doa tertentu sesuai dengan keinginan masyarakat yang ingin melakukan persembahan atau pelepasan hewan. Bentuk struktur pelaksanaannya diwujudkan dengan tahapan-tahapan tertentu. Pertama berkumpul di Saoraja lalu ke Salo, kemudian kembali ke Saoraja ma'genrang (memainkan gendang), mabbaca (membaca doa), dan manre (makan), dan tahapan terakhir ke Bulu Posso.

Berdasarkan Rangkaian acara dalam pelaksaan Mangngade di Desa Wanuawaru, tergambar sebuah kebudayaan masa lalu yang berlangsung di hari ini. Tingkah laku ini merupakan bentuk aktivitas masyarakat yang terhubung dengan kehidupan masa lalu para leluhur mereka. Mereka masih memegang teguh dan menjalankan aktivitas tersebut meskipun telah hidup dalam kebudayaan sekarang dan telah menganut agama Islam. Hal yang tidak terlihat dalam acara Mangngade, yaitu tidak adanya aktivitas yang berkaitan dengan legitimasi sosial seperti pada pelaksanaan di situs megalitik lainnya di Sulawesi Selatan, tetapi keberadaan pemimimpin, tingkah laku yang bersifat komunal, dan pengaruh ekonomi tercermin dalam aktivitas Mangngade. Mangngade dengan penggunaan media alam berupa batu, adanya persembahanpersembahan, serta pengharapan terhindar dari amarah bahaya yang berasal dari kultus nenek moyangnya merupakan ciri tingkahlaku tradisi megalitik yang masih dijalankan oleh masyarakat desa Wanuawaru.

Aktivitas yang telah dilaksanakan oleh masyarakat Desa Wanuawaru dalam acara Mangngade merupakan realitas masa sekarang yang mencerminkan tingkah laku masa lalu. Kondisi itu tidak lepas dari akulturasi dari kebudayaan masa sekarang. Unsur budaya masa sekarang dapat ditemui pada penggunaan Saoraja yang sifatnya simbolik, pengunaan gendang, penggunaan jas tutup dan songko oleh sanro ade', kehadiran para penjual yang menjajakan berbagai makanan di sekitar Batu Melingkar di Bulu Posso, dan persembahan hewan kambing.

Disamping itu, penggunaan kata Manggade oleh masyarakat Wanuawaru merupakan pemaknaan yang tampaknya terbangun diperiode sejarah, yaitu ketika kerajaan-kerajaan di Sulawesi Selatan telah terbentuk. Selain itu, Manggade merupakan pengingat terhadap leluhur dan kampung halaman bagi para keturunan asal Desa Wanuawaru yang telah hidup dalam perantauan . Oleh karena itu, Mangngade merupakan wujud atau simbol masyarakat Wanuawaru sebagai pengakuan keberadaan kelompoknya. 


\section{PENUTUP}

Mangngade atau 'menjalankan adat' yang dilaksanakan di Desa Wanuawaru terdiri atas tiga tahap, yaitu mengunjungi salo, berkumpul di saoraja, dan berkumpul di Bulu Posso. Kegiatan masyarakat mengunjungi salo diwujudkan melalui ritual maccera yang berkaitan dengan pertanian, yaitu agar terhindar dari bencana alam berupa banjir dan angin kencang sehingga hasil panen tetap baik. Ke dua, berkumpul di saoraja diwujudkan dengan maggenrang, ma'baca, dan manre. Di tempat ini, kegiatannya dikaitkan dengan kehidupan. Ke tiga, berkumpul di Bulu Posso. Kegiatan di tempat ini diwujudkan dengan ritual di batu melingkar, yaitu pelepasan ayam, doadoa pada orang yang berniat melakukan sesuatu dan doa-doa tehadap orang-orang atas kesyukuran karena niatnya telah terwujud. Selain itu, maccera pada tempat ini berkaitan dengan harapan kedamaian.

Berdasarkan pengamatan yang telah berlangsung dalam acara Mangngade, maka kegiatan tersebut menunjukan sebuah ritual yang berasal dari masa lalu. Penggunaan media alam, seperti sungai, bukit, batu, dupa, penyembelihan hewan, dan pelepasan hewan disertai dengan doa-doa dan niat tertentu merupakan wujud tingkahlaku dalam budaya megalitik. Selain itu, penggunaan kata Manggade pada acara ini merupakan istilah yang muncul pada periode kerajaan sehingga acara Manggade juga tak lepas dari simbol identitas yang didasari dengan penghormatan terhadap leluhur dan kampung halaman. Oleh karena itu, Mangngade merupakan sebuah ritual yang dijalankan oleh masyarakat Desa Wanuawaru dengan mempertahankan pengetahuan leluhur mereka dalam membangun pengakuan keberadaan kelompoknya. Karena itu, Manggade adalah perwujudan simbol kelompok yang bercirikan tradisi megalitik.

\section{Ucapan Terima Kasih}

Terima kasih kepada Andi Syahru Ramadhan yang telah menemani penulis mengunjungi acara Mangngade di Desa Wanuawaru. Tak lupa pula penulis ucapkan terima kasih kepada bapak Rudi, Amir, dan Monro yang bersedia memberikan informasi mengenai pelaksanaan acara Mangngade. Terakhir, ucapan terima kasih kepada warga Desa Wanuawaru yang telah menerima dengan baik kedatangan penulis mengamati prosesi ini.

\section{DAFTAR PUSTAKA}

Andari, C. (2001). Aspek Megalitik Situs Sewo, Soppeng. Walennae, 4(6), 13-22.

Andari, C. (2006). Komplesk Megalitik Sewo, Soppeng: Tinjauan Awal Terhadap Periodesasi dan Interpretasi. Walennae, 107-120.

Duli, A. (2008). Bentuk dan Peranan Budaya Megalitik Pada Beberapa Situs Di Kabupaten Bantaeng. Walennae, 10(4), 19-43.

Harris, D. R. (2006). The Interplay of Ethnographic and Archaeological Knowledge in the Study of Past Human Subsistence Tropics. Royal Anthropological Institu, 63-78.

Hasanuddin. (2011a). Peninggalan Megalitik Di Situs Lamatti, Tondong, Bulo-Bulo Di Sinjai Sulawesi Selatan. Walennae, 12(1), 17-28. 
Hasanuddin. (2011b). Temuan Megalitik Dan Penataan Ruang Pemukiman Di Kabupaten Enrekang. Walennae, 12(1), 159-168.

Hasanuddin. (2016). Nilai-Nilai Sosial dan Religi dalam Tradisi Megalitik di Sulawesi Selatan. Kapata Arkeologi, 12(2), 191-198.

Pinasti, V. I. (2007). Diktat Etnografi Indonesia. Yogyakarta: Universitas Negeri Yogyakarta.

Simanjuntak, T., \& Widianto, H. (2012). Indonesia dalam Arus Sejarah. Jakarta: PT. Ichtiar baru Van Hoeve dan Kemendikbud.

Suryatman. (2011). Pengelolaan Sumberdaya Budaya Di Gantarang Keke Kabupaten Bantaeng (Studi Kasus Pesta Adat Pajjukukang). Walennae, 12(1), 101-112.

Umar, A. F. (2002). Integritas Sosial dan Kultural Dalam Tradisi Megalitik Di Possi Tana, Kajang. Walennae, 5(9), 54-63. 